Research Article

\title{
Quantitative Reinforcement Analysis of Loess Slope with Anisotropy
}

\author{
Yuling Shi $\mathbb{D}^{1},{ }^{1}$ Rui Wang $\mathbb{D}^{2},{ }^{2}$ Hang Yuan $\mathbb{D}^{3},{ }^{3}$ Han Bao $\mathbb{D D}^{2}$ and Changgen Yan $\mathbb{D D}^{2}$ \\ ${ }^{1}$ School of Geological Engineering and Geomatics, Chang'an University, Xi'an 710054, Shaanxi, China \\ ${ }^{2}$ School of Highway, Chang'an University, Xi'an 710064, Shaanxi, China \\ ${ }^{3}$ Shenzhen Expressway Engineering Consulting Co., Ltd, Shenzhen 518049, Guangdong, China
}

Correspondence should be addressed to Rui Wang; wangruing@163.com

Received 30 January 2019; Accepted 14 April 2019; Published 15 May 2019

Academic Editor: Jian Ji

Copyright (C) 2019 Yuling Shi et al. This is an open access article distributed under the Creative Commons Attribution License, which permits unrestricted use, distribution, and reproduction in any medium, provided the original work is properly cited.

The loess slope in east Gansu presents a large degree of anisotropy which should be considered both in the slope stability analysis and in the reinforcement design. To investigate the mechanical anisotropy presented in the loess soil, the undisturbed loess specimens are taken from the field with different sampling directions ( $\alpha$, defined as the angle between the normal direction of specimen and sedimentation direction). The direct shear tests are conducted on specimens of different $\alpha$, and it is found that the anisotropy has slight influence on the friction angle $(\varphi)$, while the specimen with $\alpha=0^{\circ}$ presents the smallest cohesion and the specimen with $\alpha=90^{\circ}$ has the largest cohesion. The anisotropy behaviors have also been observed from the one-dimensional consolidation test and tension test. After that, the principle of point safety factor and the degree of reinforcement demand are introduced, and the method of quantitative reinforcement of anisotropic loess slope is proposed. The proposed approach is then implemented in the Fast Lagrangian Analysis of Continua in 3D $\left(\right.$ FLAC $\left.^{3 \mathrm{D}}\right)$, and the point safety factor and the degree of reinforcement demand are investigated on slope with different slope ratios. It is found that the proposed approach could effectively be used to analyze the slope involving anisotropy through the comparison with the conventional limit equilibrium method. Meanwhile, the reinforcement zone and the reinforcement demanding of anisotropy slope are obtained, and relevant reinforcement design in practice is proposed.

\section{Introduction}

The loess soil is widely distributed in Gansu, Shaanxi, and western part of Henan in China [1], and the landslide of loess slope along the highway has frequently happened for the reason of rainfall and excavation. The stability analysis and reinforcement are therefore compulsory for the loess slope. The traditional methods used in the slope stability analysis include the limit equilibrium method [2-6], the strength reduction method $[7,8]$, and the reliability-based method $[9,10]$. Moreover, Verma et al. [11] built a coupled finite element method (FEM) and artificial neural network (ANN) model to predict the factor of safety of the slope. Gao et al. [12] developed the stability chart to analyze the 3D failure of the homogeneous slope. However, most of the approaches can only reflect the overall stability, and the safety status of each point of the slope cannot be analyzed.

Alternatively, the concept of point safety factor (PSF) proposed by Hoek and Bray [13] could capture the status of each point in the slope. The PSF is defined as the ratio of the largest shear strength on the potential slip plane to its effective shear stress for one point. Therefore, the PSF can be used to evaluate the stability of each element compared with the factor of safety. Meanwhile, the PSF yields additional insight into the geometry and location of the potential failure surface and how instability may initiate and evolve. Relevant studies include Jiang [14], who derived the PSF function characterized by Hoek-Brown parameters, and Lu et al. [15], who investigated the rainfall-induced slope instability using a field of local factor of safety. For most of the slope stability analysis, the soil in the slope is represented as an isotropic 
homogeneous material. However, the soil parameters sometimes show considerable spatial variability [16] and anisotropy $[17,18]$. The loess slope located in east Gansu presented a large degree of anisotropy, and it is necessary to take the anisotropy effect into the slope stability analysis.

Associating with the overall analysis and local analysis, the reinforcement techniques used are varying a lot. In the overall slope stability analysis, the reinforcement design is normally based on the potential failure plane, which is not economical in most circumstances. For example, Zhang et al. [19] proposed an analysis procedure for turning corner in geosynthetic-reinforced soil structures, so as to calculate the strength and length of steel bars required for internal stability. On the other hand, the reinforcement design based on the local factor safety is more rational, which could be used to analyze the initiation of the landslide. To this end, the degree of reinforcement demand (DRD) proposed by Yang et al. [20] is used for the quantitative reinforcement analysis, in which the DRD quantitative index is used to assess the degree of reinforcement demand for slope projects. However, the application of DRD can only be found in the rock slope engineering, and a relevant study related to loess slope is rarely reported.

In this paper, the concept of point safety factor and degree of reinforcement demand considering anisotropy are introduced firstly. After that, the anisotropy behavior of loess soil in east Gansu is studied through direct shear test, tension test, and one-dimensional consolidation test, and the parameters used for the stability analysis are obtained. After that, the concept of PSF and DRD are compiled by FISH in FLAC $^{3 \mathrm{D}}$ to design the slope reinforcement scheme with different types of slope. The rationality and economy of the quantitative reinforcement design method are proved with relevant conclusion provided at the end of this paper.

\section{Methodology}

2.1. Concept of DRD. The DRD is proposed based on the method of point safety factor, in which the slope is stable if every point on the slip plane is safe, with the expression of

$$
K_{p}=\frac{c^{\prime}+\sigma \tan \varphi^{\prime}}{\tau} .
$$

However, the loess soil presents a behavior of anisotropy. To consider the anisotropy into the point safety factor, the shear strength parameter should be chosen according to the direction of failure plane, and the point safety factor is revised as follows:

$$
K_{p, \vec{N}}=\frac{c_{\vec{N}}^{\prime}+\sigma_{\vec{N}} \tan \varphi \frac{{ }_{N}}{\tau_{\vec{N}}}}{\tau_{\vec{N}}}
$$

where

$$
\sigma_{\vec{N}}=l^{2} \sigma_{1}+m^{2} \sigma_{2}+n^{2} \sigma_{3}
$$

$\sqrt{l^{2} \sigma_{1}^{2}+m^{2} \sigma_{2}^{2}+n^{2} \sigma_{3}^{2}-\sigma_{n}^{2}}, \vec{N}$ refers to the normal direction for any plane in soil element, $l, m$, and $n$ are direction vectors of $\vec{N}, \sigma_{1}, \sigma_{2}$, and $\sigma_{3}$ are principal stresses, and $c_{\vec{N}}^{\prime}$ and $\varphi \frac{\prime}{N}$ are directional cohesion and friction, respectively, as obtained from the experimental results.
If the soil element is subjected to tensile failure, the point safety factor is expressed as follows:

$$
K_{p, \vec{N}}=\frac{\sigma_{t, \vec{N}}}{-\sigma_{3}} .
$$

Then, the point safety factor is summarized as $K_{p}=$ $\min \left[\min \left(K_{p, \vec{N}}\right), K_{t}\right]$ based on the calculation result for a certain range of normal directions, e.g., $0^{\circ} \sim 180^{\circ}$ with an interval of $10^{\circ}$.

As illustrated in Figure 1, if the angle between a section (normal vector is $\vec{N}$ ) and the maximum principal stress plane is $\gamma$, the point safety factor of the section is expressed as follows:

$$
\begin{aligned}
K_{d}= & \frac{\tau_{c \vec{N} k}}{\tau_{\vec{N} k}} \\
= & \frac{\tan \varphi_{\vec{N}}^{\prime}\left[\sigma_{1}+\sigma_{3 \vec{N} k}+\left(\sigma_{1}-\sigma_{3 \vec{N} k}\right) \cos 2 \gamma\right]+2 c \vec{N}}{\left(\sigma_{1}-\sigma_{3 \vec{N} k}\right) \sin 2 \gamma},
\end{aligned}
$$

where $\tau_{c \vec{N} k}$ is the shear strength, $\tau_{N_{N}}$ is the shear stress, $\sigma_{1}$ is the major principal stress, $\sigma_{3 \vec{N} k}$ is the minor principal stress, and $\sigma_{3}$ is the required minor principal stress at failure state.

Following this, the degree of reinforcement demand is defined as follows:

$$
\begin{aligned}
\Delta \sigma_{3 \vec{N}} & =\sigma_{3 \vec{N} k}-\sigma_{3} \\
& =\frac{\left[K_{d} \sin 2 \gamma-\tan \varphi \frac{\prime}{N}(1+\cos 2 \gamma)\right] \sigma_{1}-2 c \vec{N}}{K_{d} \sin 2 \gamma+\tan \varphi \frac{\prime}{N}(1-\cos 2 \gamma)}-\sigma_{3} .
\end{aligned}
$$

If the soil is subjected to tension stress, the degree of reinforcement demand is obtained as $\Delta \sigma_{3 t}=\sigma_{3 k}-$ $\sigma_{3}=-\sigma_{t} / K_{d}-\sigma_{3}$. Then, the degree of reinforcement demand is obtained as $\Delta \sigma_{3}=\max \left[\max \left(\Delta \sigma_{3 \vec{N}}\right), \Delta \sigma_{3 t}\right]$ considering both tensile failure and shear failure.

2.2. Anisotropy in FLAC ${ }^{3 D}$. The FLAC ${ }^{3 \mathrm{D}}$ (Fast Lagrangian Analysis of Continua in 3 dimensions) based on the explicit finite difference method is commercial software developed by ITASCA [21]. Due to its simple operation and accurate algorithm, it is widely used in the simulation of mechanical properties of geomaterials. Meanwhile, the built-in FISH could extend the FLAC ${ }^{3 \mathrm{D}}$ to a wide range of application [22].

The FLAC ${ }^{3 \mathrm{D}}$ is adopted in this study to investigate the point factor safety and degree of reinforcement demanding of loess slope with anisotropy. In this study, the composite failure criteria that consist of traditional Mohr-Coulomb shear yield criterion and the tensile yield criterion are used, which are expressed as follows:

$$
\begin{aligned}
H_{1}(\sigma, \vec{N}) & =-\sigma_{\vec{N}} \tan \varphi_{\vec{N}}+c_{\vec{N}}-\tau_{\vec{N}}, \\
F_{1}(\sigma) & =\sigma_{t}-\sigma_{1} .
\end{aligned}
$$




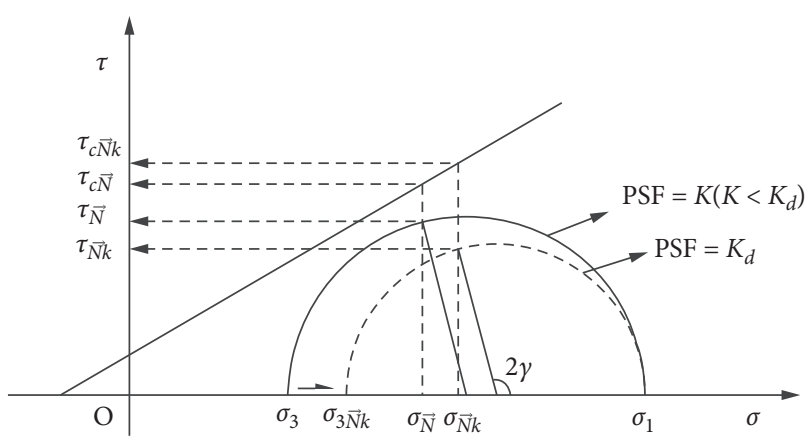

FIgURE 1: Schematic diagram of definition for DRD.

In anisotropic materials, the friction angle and cohesion are directional dependents. In order to realize the anisotropy in FLAC ${ }^{3 \mathrm{D}}$, the strength parameter cohesive force $c$ and the friction angle $\varphi$ should be chosen differently at different directions according to experimental results. For tensile yielding, only the minimum principal stress acting surface is considered to yield, and the corresponding tensile yielding function is

$$
F_{2}(\sigma)=\sigma_{t 3}-\sigma_{3},
$$

where $\sigma_{t 3}$ is the tensile strength on the active surface of the minimum principal stress.

Under anisotropic conditions, the condition that the soil enters yielding is that there is the section $\vec{N}_{0}$ such that a certain yield function is less than 0 , which are expressed as

$$
\min _{|\vec{N}|=1}\left[H_{2}(\sigma, \vec{N}), F_{2}(\sigma)\right]=0
$$

where $|\vec{N}|=1$ represents all spatial unit vectors.

To this end, the realization of the anisotropy in FLAC ${ }^{3 \mathrm{D}}$ is demonstrated in Figure 2.

To include the anisotropic property in the point safety factor and degree of reinforcement demand, the strength parameters have to be obtained from the laboratory experiments, which is presented in the next part.

\section{Experimental Study of Anisotropic Behavior of Loess Soil}

The material used in this study is the loess soil taken from Gansu in China, as shown in Figure 3. The particle size distribution of loess soil in this area is shown in Figure 4, and the wet density and water content are $1.65 \mathrm{~g} / \mathrm{cm}^{3}$ and $11.6 \%$, respectively. The anisotropic property of loess soil can be reflected both in strength and deformation. Accordingly, the direct shear test, tensile test, and compression test are conducted which are presented as follows.

3.1. Direct Shear Test. To investigate the influence of anisotropy on the shear strength of soil, the cylinder specimens are taken from the undisturbed loess brick along different directions. The specimen has a diameter of $6.18 \mathrm{~cm}$ and height of $2 \mathrm{~cm}$, and the direction is defined as the angle $\alpha$ between the normal direction of specimen and

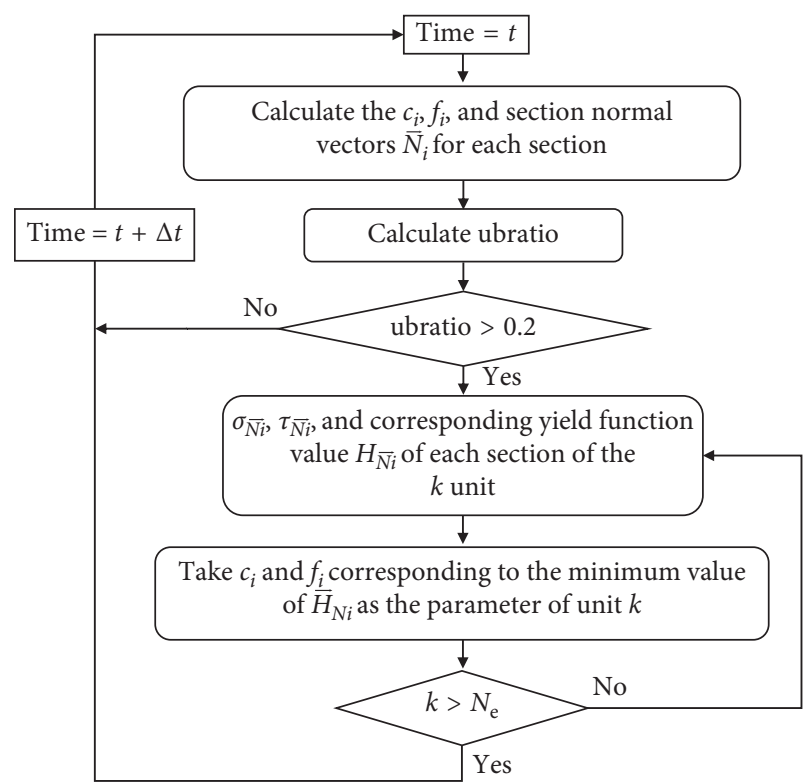

Figure 2: Program sketch of FLAC $^{3 \mathrm{D}}$ using orthotropic yield criterion.

sedimentation direction (vertical), as demonstrated in Figure 5. The direct shear test is conducted at different normal stresses ranging from $50 \mathrm{kPa}$ to $200 \mathrm{kPa}$. To obtain reliable results, for each of the test condition, three tests are conducted, with selected results presented in Figure 6.

The test results are summarized in Figure 7, and it is found that the friction angles roughly remain the same for specimens of different anisotropy angles. However, cohesion varies a lot for specimens taken from different directions. The specimen with directional angle of 0 exhibits the smallest cohesion, while the largest cohesion presented in the specimen with taking from the direction of $90^{\circ}$. It is concluded that anisotropy of the loess in research area is remarkable, which should be involved in the strength parameter selection during the slope stability analysis.

3.2. One-Dimensional Consolidation Test. One-dimensional consolidation tests are conducted for the specimens taken from directions $0^{\circ}$ and $90^{\circ}$ under normal stresses from $50 \mathrm{kPa}$ to $400 \mathrm{kPa}$. The compression curves are presented in Figure 8 , and the compression coefficients $a_{1-2 V}$ are calculated as $0.16 \mathrm{MPa}^{-1}$ and $0.24 \mathrm{MPa}^{-1}$ for the specimen of angles 0 and 90 , respectively, and the corresponding compression modulus is obtained as $11.09 \mathrm{MPa}$ and $7.37 \mathrm{MPa}$. It can be seen that the soil sample belongs to medium compressive soil, and the compressibility of loess soil shows significant anisotropy.

3.3. Tensile Test. According to the definition, the point safety factor of soil element subjected to tensile (equation (3)) and the criterion that related to tensile failure (equation (7)), the tensile strength is significant to the slope stability when the slope is subjected to the failure type of overturning. In this circumstance, the crack will initiate from the slope crest, and 


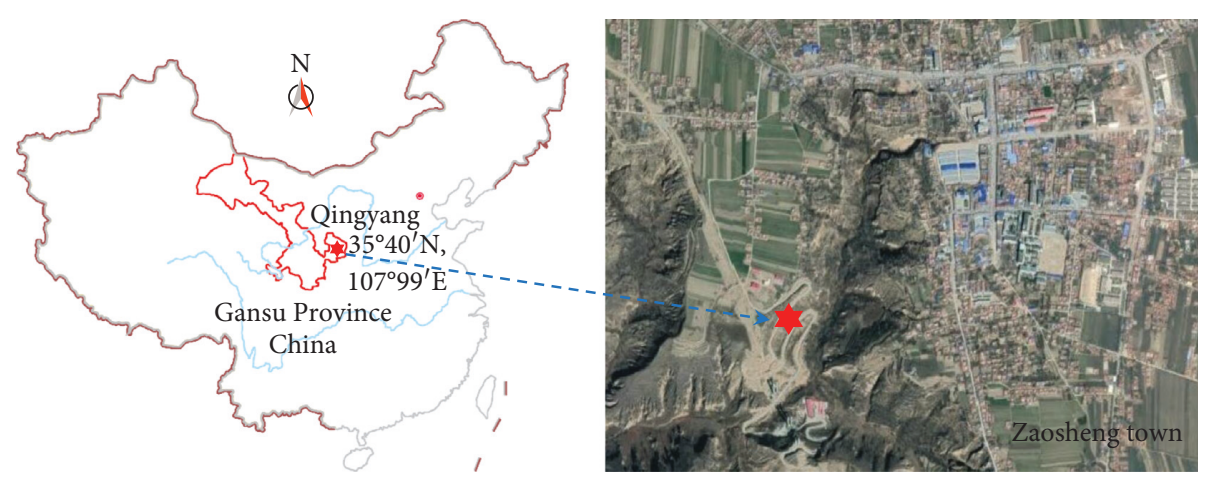

FIGURE 3: Geological location of the undisturbed loess soil.

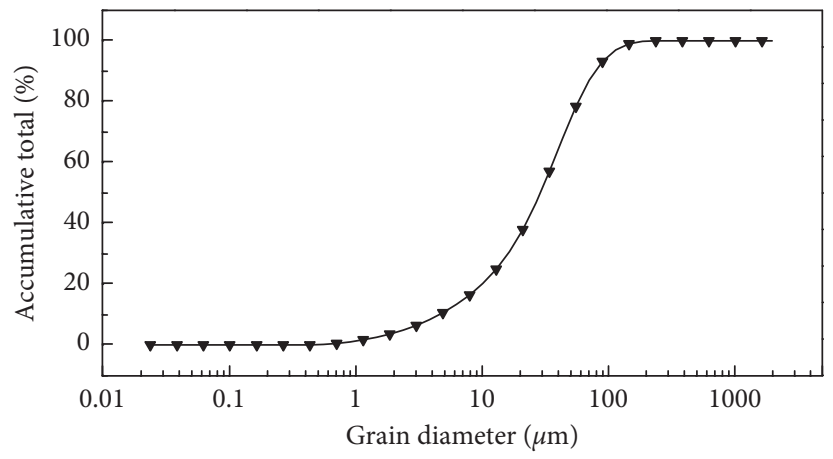

FIgURE 4: Particle size distribution of loess soil.

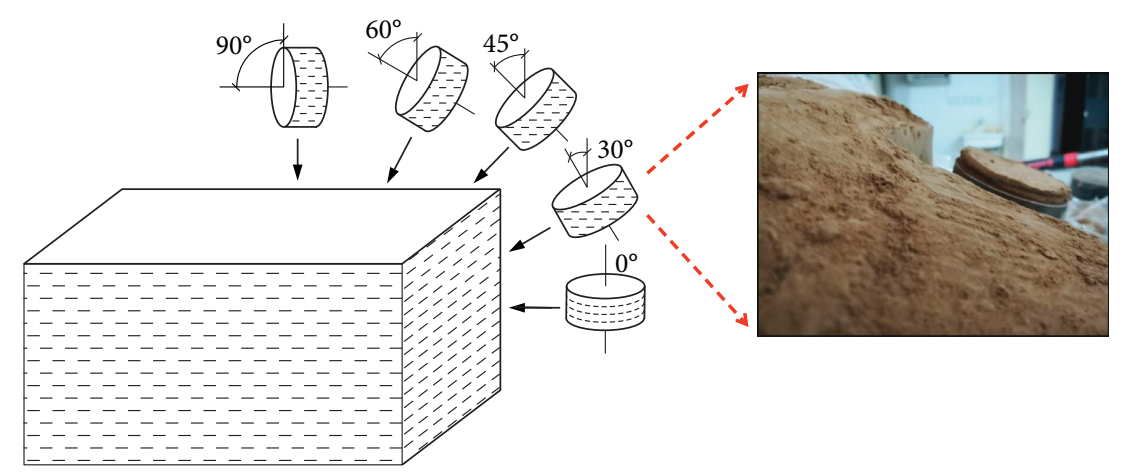

FIgURE 5: Direct shear test on the loess soil with different sampling directions.

the tensile strength will have significant influence on the stability of slope. Therefore, the experimental investigation on the tensile strength is compulsory, which is obtained through direct tensile test. The specimen is cut from the undisturbed soil brick, which has a dimension of $4 \mathrm{~cm} \times 4 \mathrm{~cm} \times 8 \mathrm{~cm}$ and with different bedding directions, as presented in Figure 9. To ensure the accuracy of the test, the specimen is cut in the way that the cross section gradually decreases the specimen from the end part to the middle part. During the test, the specimen is fixed at one end, and the tensile force is applied evenly at the other end until tensile failure (Figure 9). The tests are repeated for three times, and the average value is issued as tensile strength. The results of direct tensile test are shown in Table 1. It is found that tensile strength of the specimen from angle 0 is higher than that of the specimen from angle 90.
Based on the results from three tests, it is concluded that the loess soil from east Gansu present a large degree of anisotropy, and the parameters obtained will be then used for the stability analysis involving anisotropy.

\section{Numerical Study of Quantitative Reinforcement Design on the Loess Slope}

4.1. Numerical Verification of FLAC ${ }^{3 D}$. In order to verify the accuracy of FLAC ${ }^{3 \mathrm{D}}$, the numerical simulation of onedimensional consolidation on the saturated soil layer is conducted. As shown in Figure 10(a), the depth of the soil layer is $10 \mathrm{~m}$ and the load of $10 \mathrm{kPa}$ is applied on the surface. Meanwhile, the drained and undrained condition is set at the top and bottom of the loess layer, respectively. Based on the 

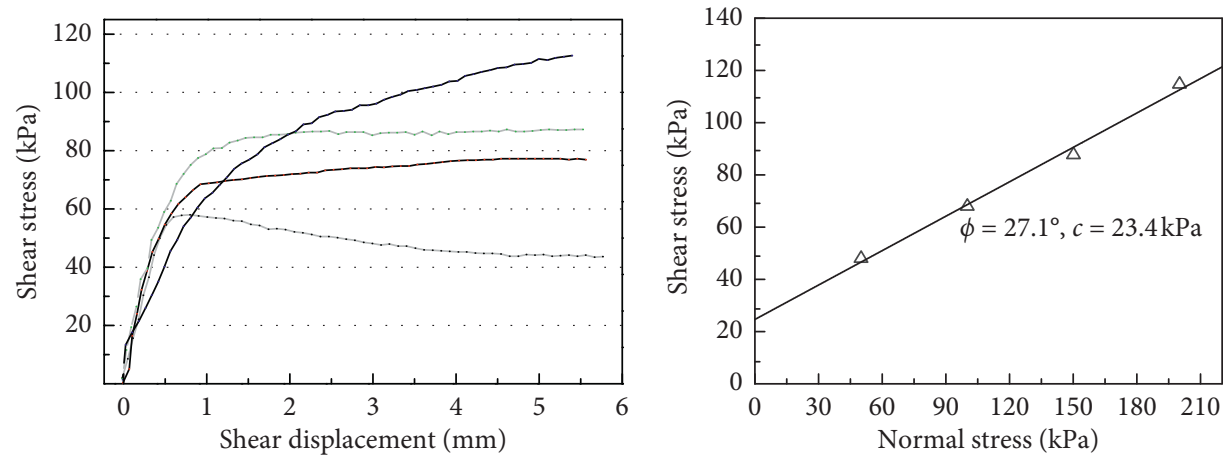

- Normal stress $=50 \mathrm{kPa}$

- Normal stress $=100 \mathrm{kPa}$

Normal stress $=150 \mathrm{kPa}$

...- Normal stress $=200 \mathrm{kPa}$

(a)

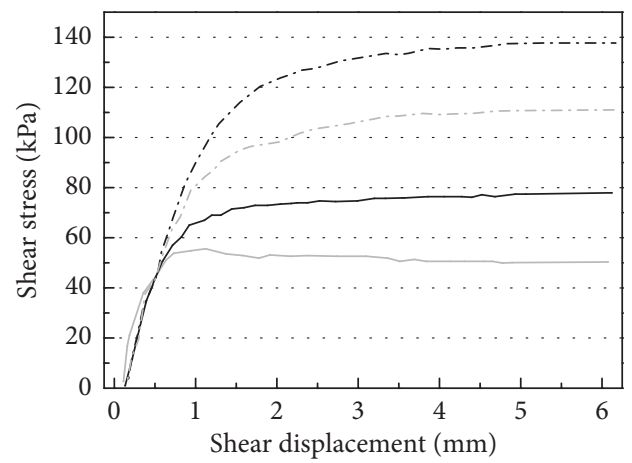

(b)

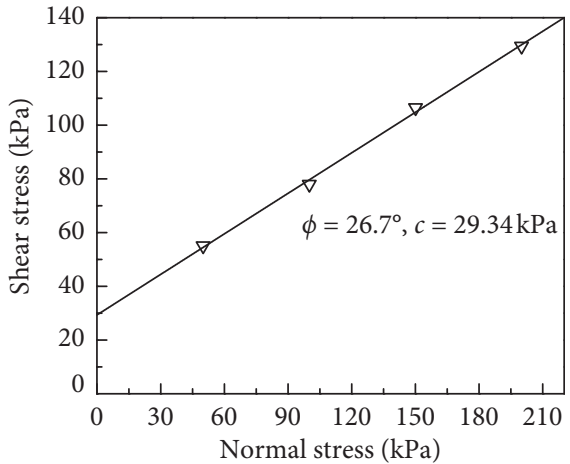

Normal stress $=50 \mathrm{kPa}$

- Normal stress $=100 \mathrm{kPa}$

Normal stress $=150 \mathrm{kPa}$

...- Normal stress $=200 \mathrm{kPa}$

(c)

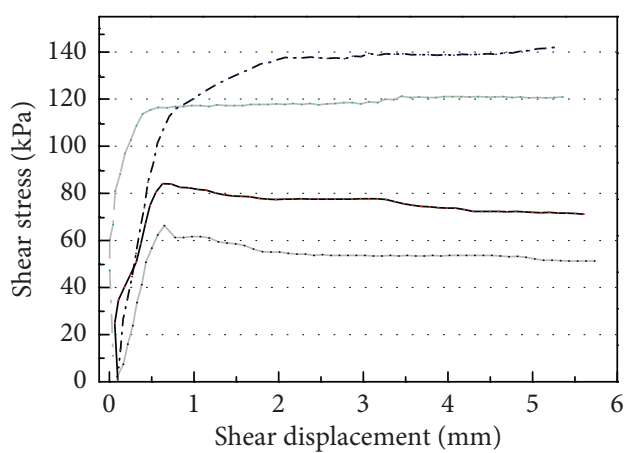

(d)

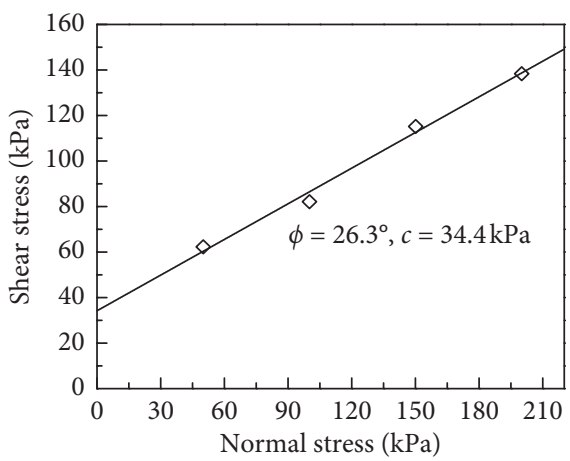

Normal stress $=50 \mathrm{kPa}$

Normal stress $=100 \mathrm{kPa}$

Normal stress $=150 \mathrm{kPa}$

...- Normal stress $=200 \mathrm{kPa}$

(e)

(f)

FIGURE 6: Stress-displacement curve for direction shear test on specimen with different sampling directions. (a) Stress-displacement curve for sample of $0^{\circ}$, (b) peak shear strength envelopes for sample of $0^{\circ}$, (c) stress-displacement curve for sample of $45^{\circ}$, (d) peak shear strength envelopes for sample of $45^{\circ}$, (e) stress-displacement curve for sample of $90^{\circ}$, and (f) peak shear strength envelopes for sample of $90^{\circ}$. 


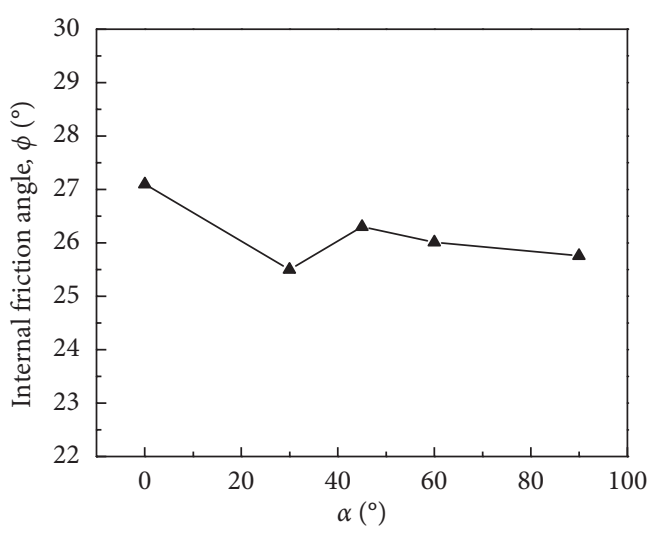

(a)

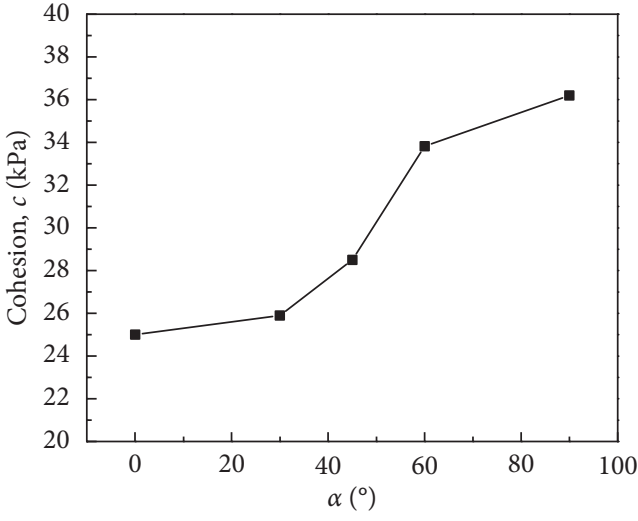

(b)

Figure 7: The shear strength parameters obtained from the shear test. The effect of direction on the (a) internal friction angle and (b) cohesion.

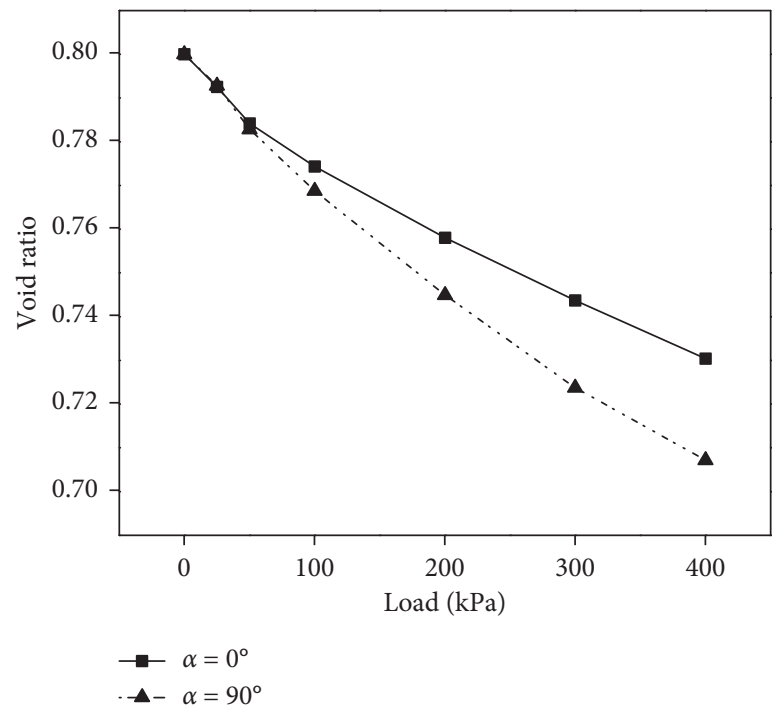

Figure 8: The e-p curve of vertical specimen and horizontal specimen.

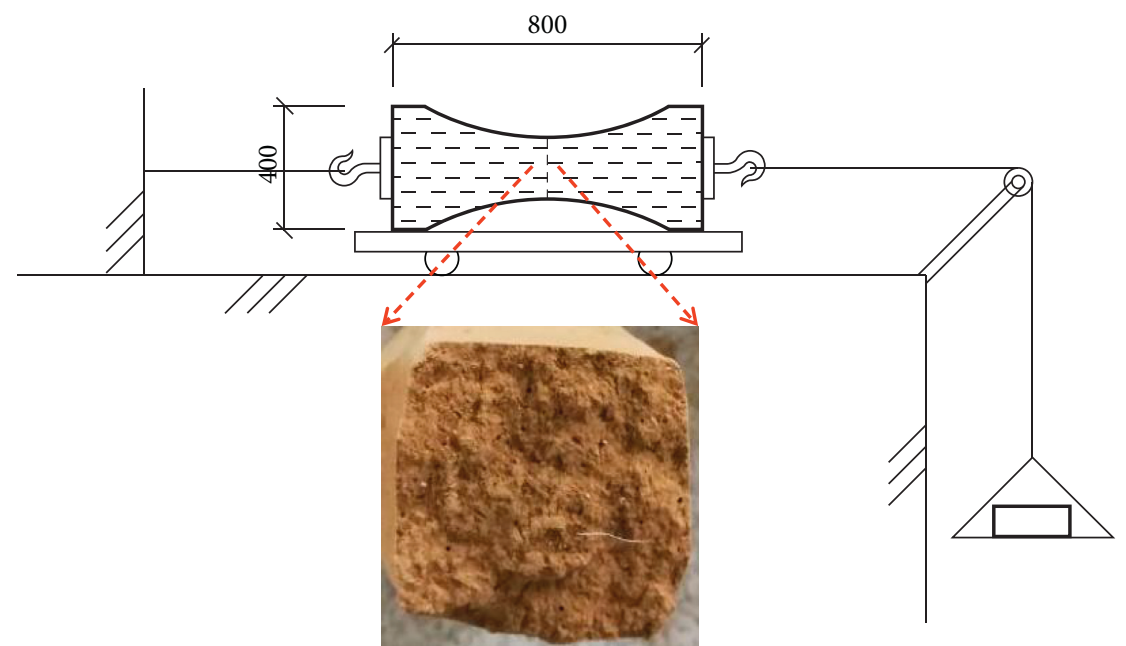

Figure 9: The diagram of tension test for sample of $0^{\circ}$. 
TABLE 1: Result of the tensile tests.

\begin{tabular}{lccccc}
\hline Specimen & \multicolumn{3}{c}{$\begin{array}{c}\text { Strength of } \\
\text { extension }(\mathrm{kPa})\end{array}$} & $\begin{array}{c}\text { Average } \\
\text { value }\end{array}$ & $\begin{array}{c}\text { Standard } \\
\text { deviation }\end{array}$ \\
\hline$\alpha=0^{\circ}$ & 15.05 & 13.67 & 9.84 & 12.85 & 2.2 \\
$\alpha=90^{\circ}$ & 9.43 & 10.22 & 11.34 & 10.33 & 0.78 \\
\hline
\end{tabular}

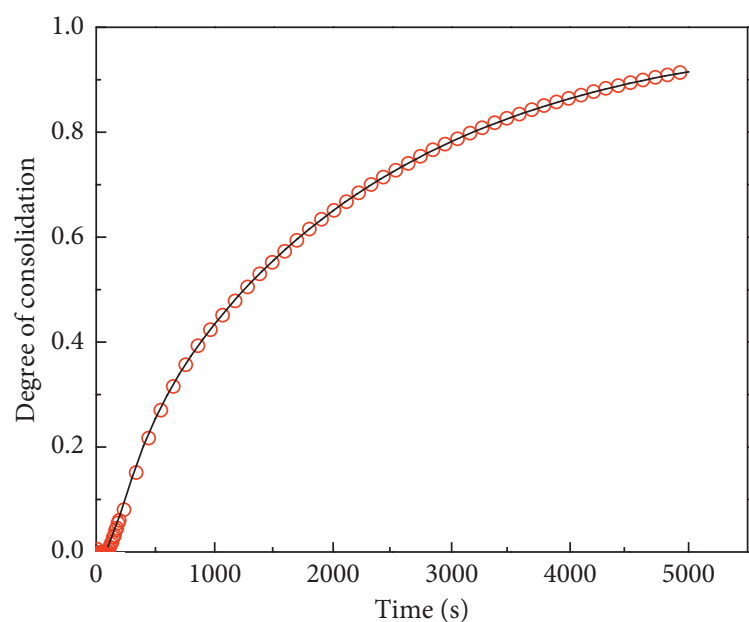

- Numerical simulation

_ Theoretical simulation

Figure 10: Comparison between theoretical solution and numerical simulation.

one-dimensional consolidation theory, the theoretical solution of the proposed problem can be expressed as follows:

$$
p_{0}=\frac{\alpha}{\alpha_{1}} \frac{1}{S} p_{z}
$$

where $p_{0}$ is the initial pore pressure, $\alpha$ is the Biot coefficient, $p_{z}$ is the external load, and $S$ is the storage coefficient expressed by

$$
S=\frac{1}{M}+\frac{\alpha^{2}}{\alpha_{1}},
$$

where $M$ is the Biot modulus, $\alpha_{1}$ is the coefficient expressed as $\alpha_{1}=K+(4 / 3) G, G$ is the shear modulus, and $K$ is the bulk modulus given by $K=E / 3(1-2 \mu)$.

Accordingly, the degree of consolidation $U$ is solved as follows:

$$
U=1-\frac{p}{p_{z}}=1-2 \frac{p_{0}}{p_{z}} \sum_{m=0}^{\infty} \frac{\sin \left(a_{m} \widehat{z}\right)}{a_{m}} e^{-a_{m}^{2} \hat{\tau}},
$$

where $a_{m}=\pi / 2(2 m+1), \quad \widehat{z}=H-z / H, \quad \widehat{t}=c t / H^{2}$, and $\alpha_{1}=K+(4 / 3) G$.

The parameters used in the numerical simulation of onedimensional consolidation problem are listed in Table 2, and the corresponding theoretical solution and numerical result are obtained, as demonstrated in Figure 10. The good agreement between the numerical simulation and analytical solution indicates that the FLAC ${ }^{3 \mathrm{D}}$ could be effectively used to solve the problem related to the geomechanics.
TABLE 2: The mechanical parameters of one-dimensional consolidation test.

\begin{tabular}{lccccc}
\hline Parameter & $M(\mathrm{GPa})$ & $\alpha$ & $k\left(\mathrm{~cm} \cdot \mathrm{s}^{-1}\right)$ & $E(\mathrm{MPa})$ & $\mu$ \\
\hline Value & 4 & 1 & $1 e-4$ & 12 & 0.35 \\
\hline
\end{tabular}

4.2. Quantitative Reinforcement Design Method. Based on the numerical validation of FLAC ${ }^{3 \mathrm{D}}$ and the concept provided, the numerical simulation based on FLAC ${ }^{3 \mathrm{D}}$ is conducted for the loess slope with anisotropy. The slope angle is $75^{\circ}$ and height is $12 \mathrm{~m}$ with boundary conditions as follows: the bottom of the model is fixed, the horizontal displacement is constrained on both sides, and the model is subjected to the gravity of $9.81 \mathrm{~m} / \mathrm{s}^{2}$. Assume that the safety factor required for slope reinforcement is 1.3. The mechanical parameters of the slope obtained from the laboratory test are shown in Table 3.

The point safety factor and the corresponding degree of reinforcement demand are obtained from FLAC ${ }^{3 \mathrm{D}}$ which is presented in Figure 11. In this article, define $\Delta \sigma_{3}$ 's azimuth as being $\theta$ for the convenience of design, as shown in Figure 11(c).

According to the distribution of the PSF, the size of the reinforcement area, the length $L$ of the prestressed anchor cable, and its arrangement on the slope surface can be determined. For example, according to the safety factor $K_{d}=1.3$ required by the standard, the reinforcement range required for the prestressed anchor cable can be determined, as shown by the dashed line in Figures 11(a) and 11(b). Using the direction angle of $\Delta \sigma_{3}$, the arrangement direction $\beta$ of the prestressed anchor cable can be determined. Finally, the arrangement of the prestressed anchor cable is obtained.

Meanwhile, stress increment $\left(\Delta \sigma_{3}\right)$ required for each unit is calculated in FLAC ${ }^{3 \mathrm{D}}$ for each element based on equation (5). Then, the anchoring force $P$ of the single anchor can be obtained as follows:

$$
P=\Delta \sigma_{3} A,
$$

where $A$ is the area covered by each bundle of prestressed anchor cables.

4.3. Comparison and Verification. In order to evaluate the quantitative reinforcement method, the quantitative reinforcement analysis method is applied to three different conditions, as listed in Table 4, which is compared with the design scheme based on the simplified Bishop method. Additional load is $2 \mathrm{~m}$ beyond the top of the slope, and factor (FS) is obtained by the strength reduction method.

Based on the fields of stresses and strength parameters of the slope, the fields of DRD and the azimuth angle $\theta$ of the $\Delta \sigma_{3}$ (shown in Figures 12(a) and 12(b)) are computed to determine the understable area of the slope, as shown by the dotted line in Figure 12(c). The arrangement range and reinforcement depth $L$ are determined. According to the azimuthal of $\Delta \sigma_{3}$, the azimuth angle of the prestressed anchor cable could be obtained. Then, anchorage force $P$ of the prestressed anchor cable is calculated from the largest 
TABLE 3: The mechanical parameters of slope.

\begin{tabular}{lccccccc}
\hline \multirow{2}{*}{ Parameter } & $\gamma\left(\mathrm{kN} \cdot \mathrm{m}^{-3}\right)$ & \multicolumn{2}{c}{$c(\mathrm{kPa})$} & \multicolumn{2}{c}{$t(\mathrm{kPa})$} & \multicolumn{3}{c}{ Horizontal direction } & Vertical direction & $\varphi\left({ }^{\circ}\right)$ & Vertical direction & Horizontal direction & $E(\mathrm{MPa})$ & $\mu$ \\
& 16.2 & 35 & 25 & 24 & 10 & 13 & 12 \\
\hline Value & & & & & 0.35 \\
\hline
\end{tabular}

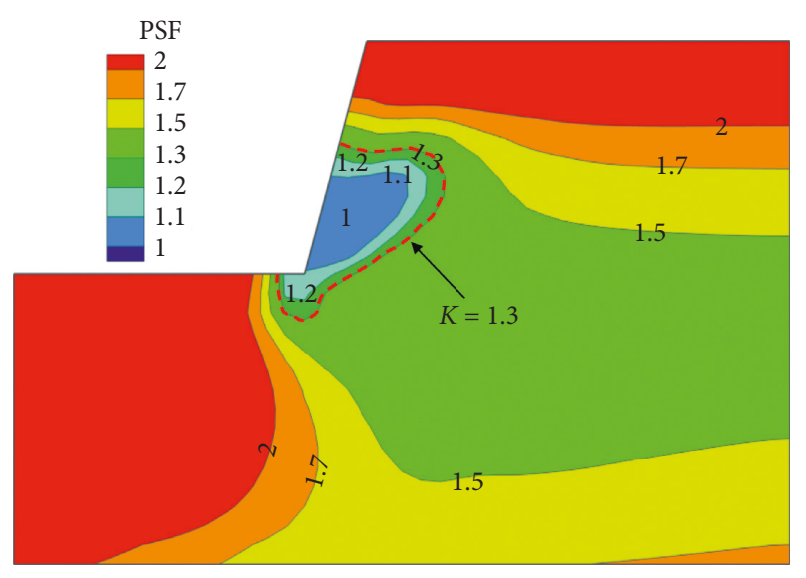

(a)

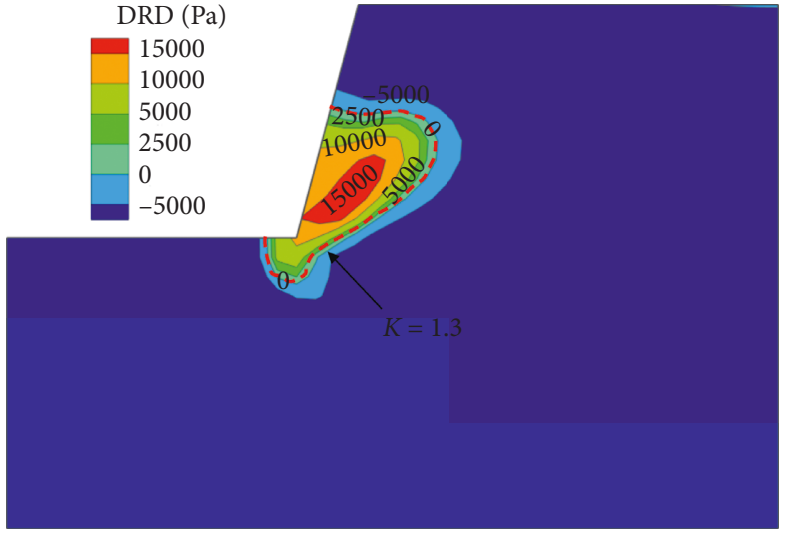

(b)

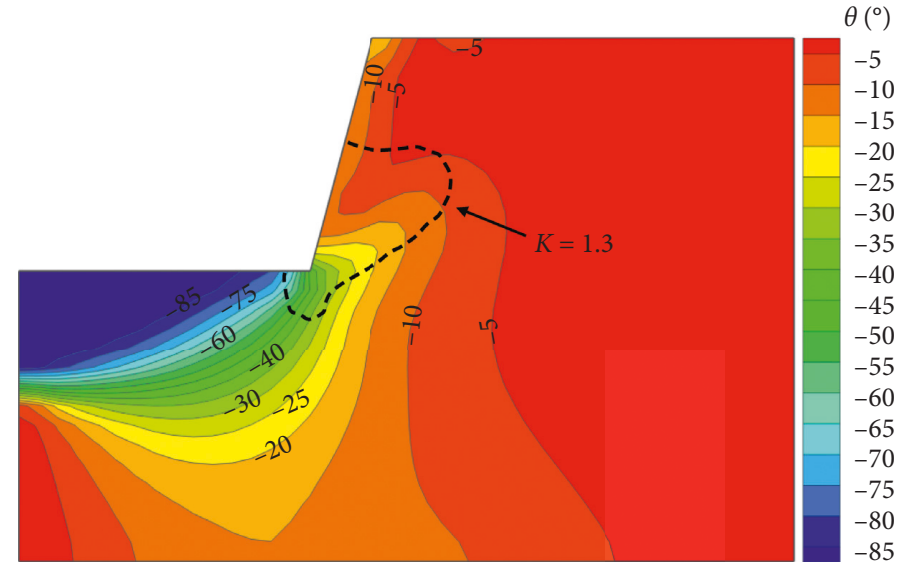

(c)

Figure 11: Numerical simulation result of slope with anisotropy. (a) Point safety factor, (b) degree of reinforcement demanding, and (c) the azimuth $(\theta)$ of $\Delta \sigma_{3}$.

TABLE 4: Design condition.

\begin{tabular}{|c|c|c|c|c|}
\hline Working condition & Slope angle $\left({ }^{\circ}\right)$ & Slope height $(\mathrm{m})$ & Additional load $(\mathrm{kPa})$ & FS \\
\hline 1 & 90 & 12 & 0 & 1.01 \\
\hline 2 & 75 & 12 & 50 & 1.04 \\
\hline 3 & 60 & 12 & 80 & 1.13 \\
\hline
\end{tabular}

DRD in the reinforcement range according to equation (12). Finally, the reinforcement scheme R1 designed by the quantitative reinforcement method is obtained. Meanwhile, the potential failure surface of the slope identified by Bishop's simplified method is presented in Figure 12(d) (dotted line). And the anchoring force is determined from the residual sliding force, and the reinforcement scheme R2 designed by Bishop's simplified method is also obtained. According to the technical requirement, the nominal diameters of prestressed anchor cables are set as $25 \mathrm{~mm}$, the tensile strength is $310 \mathrm{MPa}$, and the elasticity modulus and Poisson ratio are set as $200 \mathrm{GPa}$ and 0.2 , respectively. The reinforcement scheme of the prestressed anchor cable is indicated in Figure 12. The results show that, compared with the traditional design method, the DRDbased design method is economical and effective. To convince this, the numerical simulations are also conducted on slope with different slope ratios. 


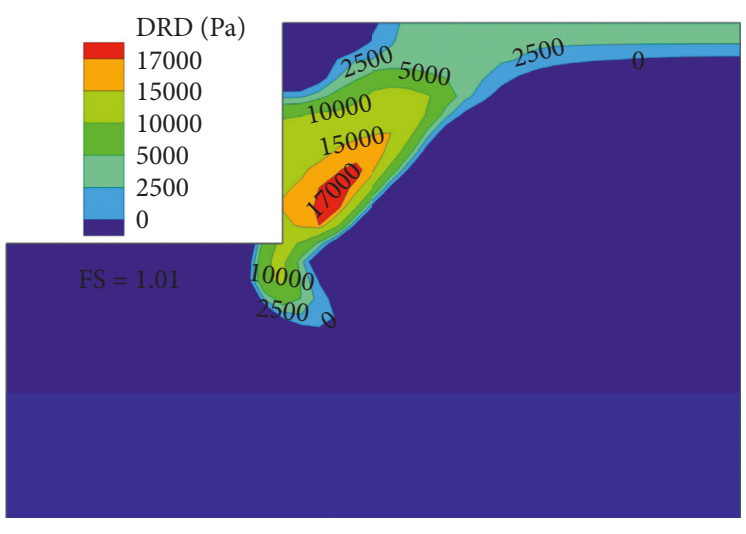

(a)

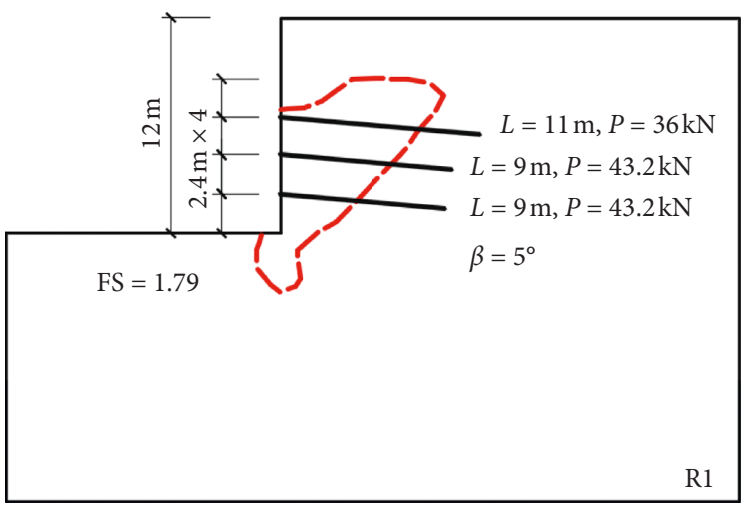

(c)

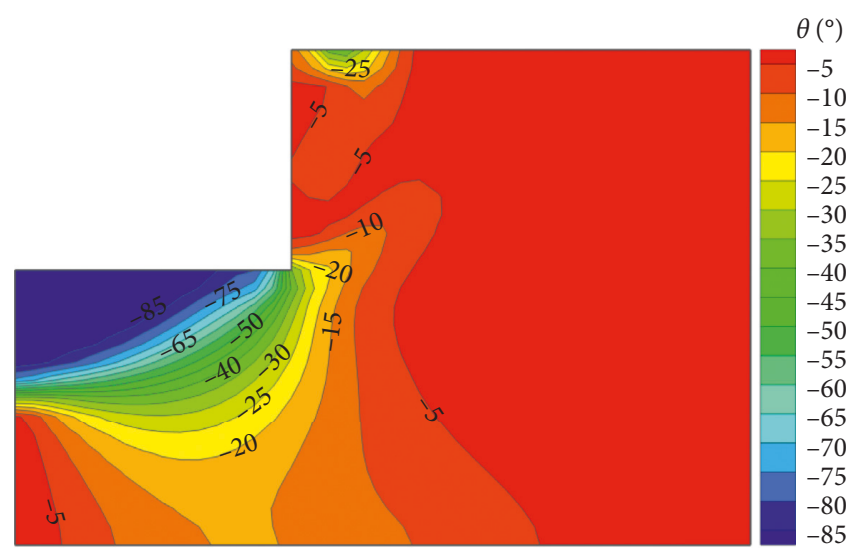

(b)

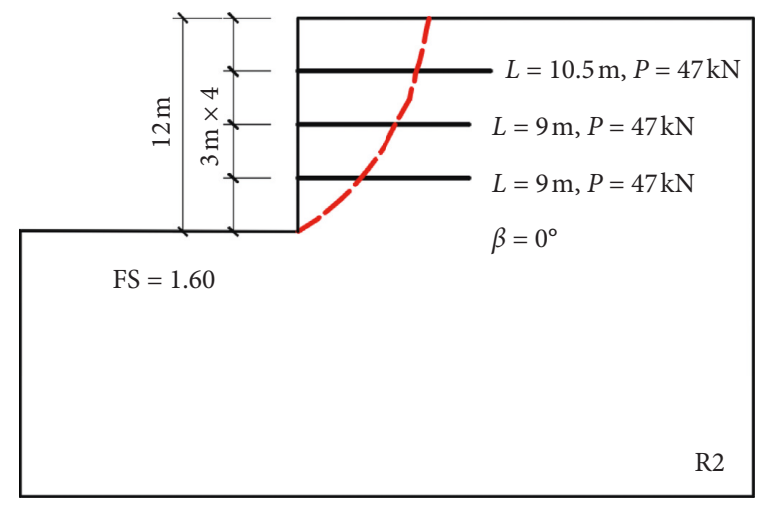

(d)

FIGURE 12: Design and comparison of reinforcement scheme at $90^{\circ}$ slope. (a) The contour map of DRD for $90^{\circ}$ slopes, (b) the azimuth of $\Delta \sigma_{3}$ for $90^{\circ}$ slopes, (c) reinforcement design of quantitative reinforcement analysis, and (d) reinforcement design of Bishop's simplified method.

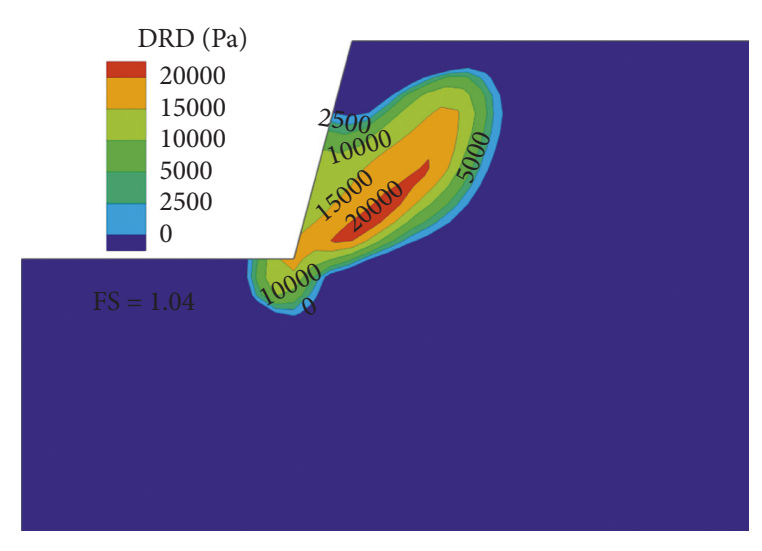

(a)

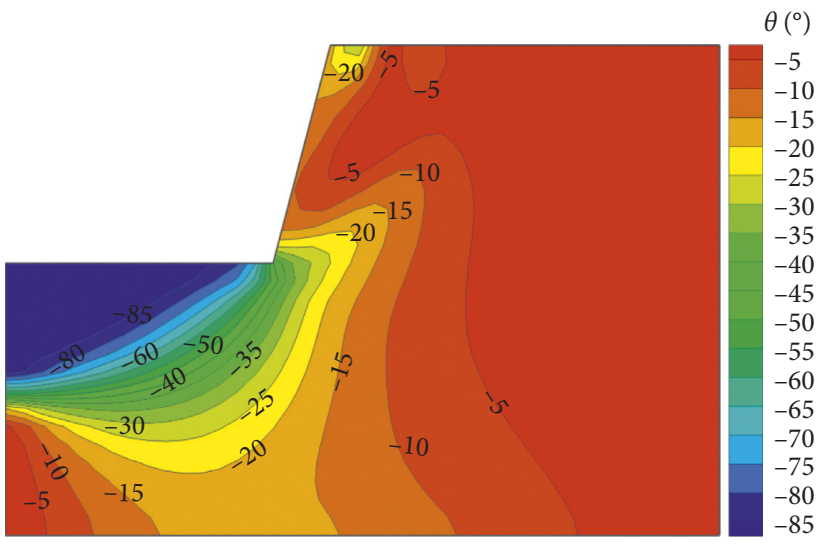

(b)

FIGURE 13: Continued. 


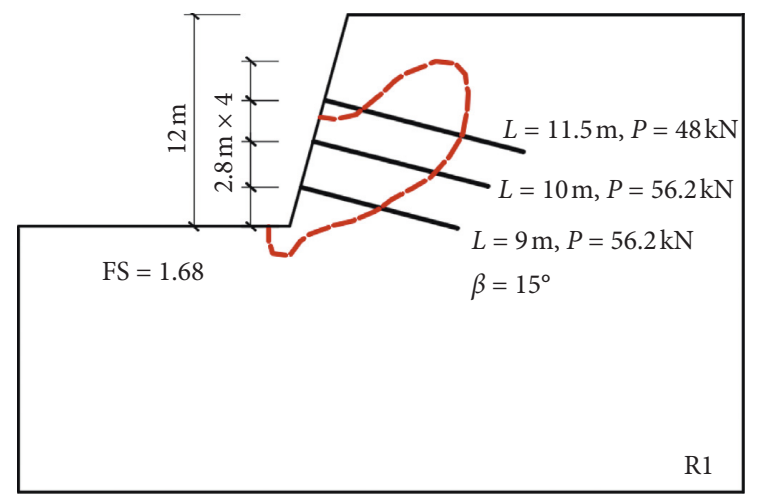

(c)

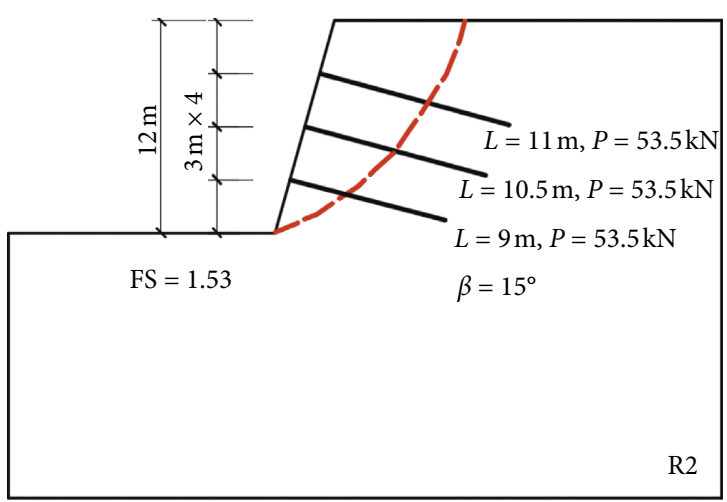

(d)

FIGURE 13: Design and comparison of reinforcement scheme at $75^{\circ}$ slope. (a) The contour map of DRD for $75^{\circ}$ slopes, (b) the azimuth of $\Delta \sigma_{3}$ for $75^{\circ}$ slopes, (c) reinforcement design of quantitative reinforcement analysis, and (d) reinforcement design of Bishop's simplified method.

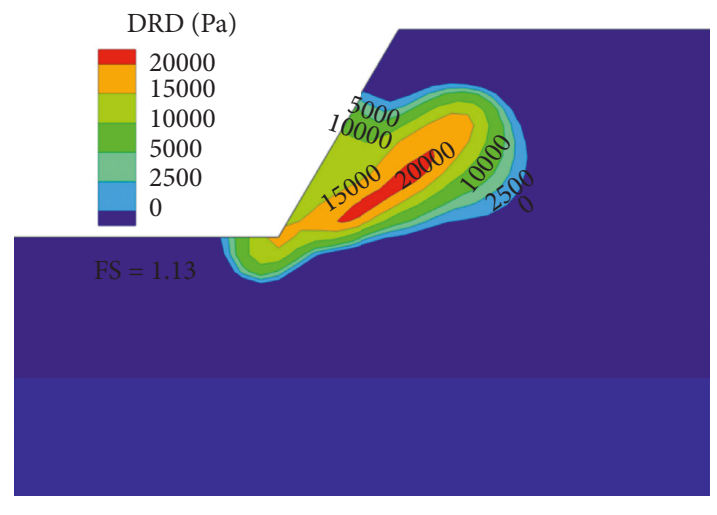

(a)

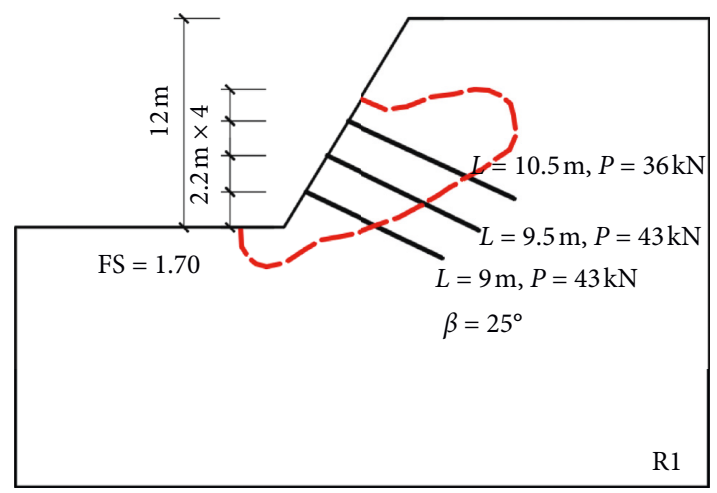

(c)

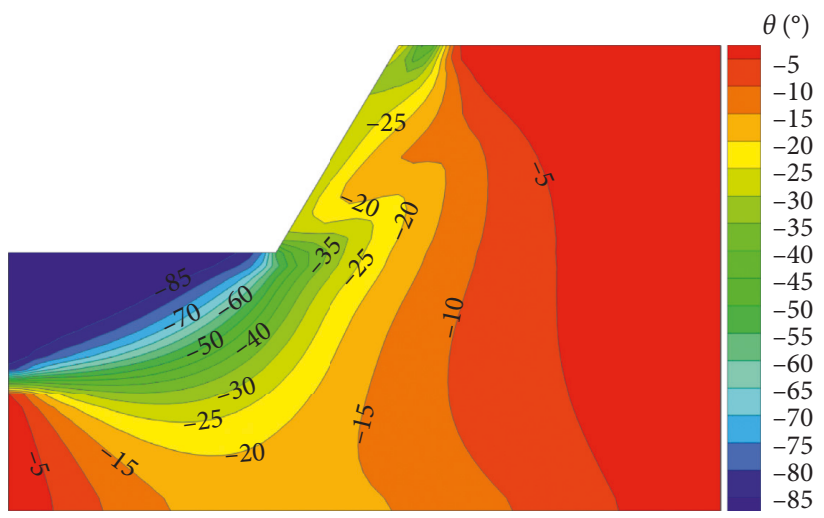

(b)

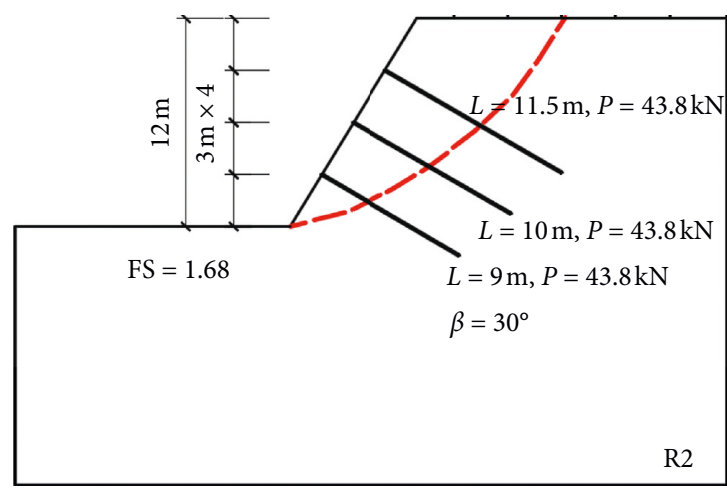

(d)

FIGURE 14: Design and comparison of reinforcement scheme at $60^{\circ}$ slope. (a) The contour map of DRD for $75^{\circ}$ slopes, (b) the azimuth of $\Delta \sigma_{3}$ for $75^{\circ}$ slopes, (c) reinforcement design of quantitative reinforcement analysis, and (d) reinforcement design of Bishop's simplified method.

Based on the simulation result from Figures 13 and 14, it is concluded that the method approach proposed is more reasonable compared with the design scheme from the traditional method, which is also consistent with the work done by $\mathrm{Lu}$ et al. [15]. Consider the progressive failure mode of the slope, the stress is concentrated on the slope foot and gradually forms a through-sliding surface, which eventually leads to the slope failure [23-25]. For the slope reinforcement design, prestress can be applied for the part of the slope, and the safety margin can be increased to avoid the formation of the through-sliding surface and the tensile crack at the top to reduce the probability of the slope being damaged. The quantitative reinforcement method shows a great advantage, and the safety factor and reinforcement demand of each part can be analyzed. 


\section{Conclusions}

The quantitative reinforcement analysis is proposed in this paper to include the anisotropy. And the anisotropic behavior of loess soil in east Gansu is experimentally investigated through direct shear test, one-dimensional consolidation test, and tensile test. The quantitative reinforcement of loess slope exhibiting anisotropy is investigated through FLAC ${ }^{3 \mathrm{D}}$, and the main conclusions can be drawn as follows:

(1) Based on the experimental result of direct shear test, it is found that the sedimentation direction has slight influence on the friction angle, and the value of cohesion depends highly on the shear direction. A difference of $47 \%$ is found for the cohesion obtained from the specimen with $\alpha=90^{\circ}$ and $\alpha=0^{\circ}$.

(2) The anisotropic behavior is also observed from onedimensional consolidation test, and it is found that the compression modulus is obtained as $11.09 \mathrm{MPa}$ and 7.37 MPa for the specimen of angles 0 and 90 . Compression modulus of the specimen with $\alpha=0^{\circ}$ is $50.5 \%$ higher than that from $\alpha=90^{\circ}$. Meanwhile, the anisotropy is also observed from the tensile test, and a slight difference is obtained.

(3) The concept of point safety factor is adopted to involve the anisotropic property, and the degree of reinforcement demanding is proposed in this study. Zones that require for the reinforcement and the force that require stabilizing the slope can be readily obtained. It can be found that the unstable region of the slope is mainly distributed in the middle and lower part of the slope. On this basis, the method and steps of quantitative reinforcement are put forward.

(4) It is concluded that the slope reinforcement design from quantitative reinforcement is more economic and efficient compared with design scheme obtained from the traditional limit equilibrium method based on the analysis of different types of slopes.

\section{Data Availability}

The data used to support the findings of this study are included within the article.

\section{Conflicts of Interest}

The authors declare that there are no conflicts of interest regarding the publication of this paper.

\section{Acknowledgments}

The research work was funded by the National Natural Science Foundation of China (Grant no. 41272285), Scientific Research Project of the Transportation Department of Gansu Province (Grant no. 2017-002), and Fundamental Research Funds for the Central Universities (Grant no. 300102218412).

\section{References}

[1] H. Zheng, H. Lin, W. Zhou et al., "Re-vegetation has increased ecosystem water-use efficiency during 2000-2014 in the Chinese loess plateau: evidence from satellite data," Ecological Indicators, vol. 102, pp. 507-518, 2019.

[2] A. W. Bishop, "The use of the slip circle in the stability analysis of slopes," Géotechnique, vol. 5, no. 1, pp. 7-17, 1955.

[3] X. P. Zhou and H. Cheng, "Analysis of stability of threedimensional slopes using the rigorous limit equilibrium method," Engineering Geology, vol. 160, no. 27, pp. 21-33, 2013.

[4] F. Vahedifard, D. Leshchinsky, K. Mortezaei, and N. Lu, "Effective stress-based limit-equilibrium analysis for homogeneous unsaturated slopes," International Journal of Geomechanics, vol. 16, no. 6, article D4016003, 2016.

[5] N. Kumar, A. K. Verma, S. Sardana, K. Sarkar, and T. N. Singh, "Comparative analysis of limit equilibrium and numerical methods for prediction of a landslide," Bulletin of Engineering Geology and the Environment, vol. 77, no. 2, pp. 595-608, 2018.

[6] Y. F. Gao, F. Zhang, G. H. Lei, and D. Y. Li, "An extended limit analysis of three-dimensional slope stability," Géotechnique, vol. 63 , no. 6, pp. 518-524, 2013.

[7] E. M. Dawson, W. H. Roth, and A. Drescher, "Slope stability analysis by strength reduction," Géotechnique, vol. 49, no. 6, pp. 835-840, 1999.

[8] Y. M. Cheng, T. Lansivaara, and W. B. Wei, "Twodimensional slope stability analysis by limit equilibrium and strength reduction methods," Computers and Geotechnics, vol. 34, no. 3, pp. 137-150, 2007.

[9] J. Ji, C. Zhang, Y. Gao, and J. Kodikara, "Effect of 2D spatial variability on slope reliability: a simplified FORM analysis," Geoscience Frontiers, vol. 9, no. 6, pp. 1631-1638, 2018.

[10] J. Ji, C. Zhang, Y. Gao, and J. Kodikara, "Reliability-based design for geotechnical engineering: an inverse FORM approach for practice," Computers and Geotechnics, vol. 111, pp. 22-29, 2019.

[11] A. K. Verma, T. N. Singh, N. K. Chauhan, and K. Sarkar, "A hybrid FEM-ANN approach for slope instability prediction," Journal of the Institution of Engineers (India): Series A, vol. 97, no. 3, pp. 171-180, 2016.

[12] Y. F. Gao, F. Zhang, G. H. Lei, D. Y. Li, Y. X. Wu, and N. Zhang, "Stability charts for 3D failures of homogeneous slopes," Journal of Geotechnical and Geoenvironmental Engineering, vol. 139, no. 9, pp. 1528-1538, 2013.

[13] E. Hoek and J. D. Bray, Rock Slope Engineering: Revised and Edition, The Institution of Mining and Metallurgy, London, UK, 1981.

[14] Q. Q. Jiang, "Stability of point safety factor of slope based on Hoek-Brown criterion," Journal of Central South University (Science and Technology), vol. 40, no. 3, pp. 786-790, 2009.

[15] N. Lu, B. Sener-Kaya, A. Wayllace, and J. W. Godt, "Analysis of rainfall-induced slope instability using a field of local factor of safety," Water Resources Research, vol. 48, no. 9, 2012.

[16] Y. Wu, X. Zhou, Y. Gao, L. Zhang, and J. Yang, "Effect of soil variability on bearing capacity accounting for non-stationary characteristics of un-drained shear strength," Computers and Geotechnics, vol. 110, pp. 199-210, 2019.

[17] Y. Mitsutoshi, "Mechanical anisotropy of undisturbed loess soil," in Proceedings of the Geotechnical Engineering Progress of the Soft Soil Area-Sino-Japanese Geotechnical Engineering Conference, vol. 12, no. 3, pp. 150-157, Tongji University Press, Shanghai, China, August 2005. 
[18] Q. Liang, J. Li, X. Wu, and A. Zhou, "Anisotropy of $\mathrm{Q}_{2}$ loess in the baijiapo tunnel on the lanyu railway, China," Bulletin of Engineering Geology and the Environment, vol. 75, no. 1, pp. 109-124, 2016.

[19] F. Zhang, D. Leshchinsky, Y. F. Gao, and S. C. Yang, "Corner reinforced slopes: required strength and length of reinforcement based on internal stability," Geotextiles and Geomembranes, vol. 47, no. 3, pp. 408-416, 2005.

[20] Z. F. Yang, L. Q. Zhang, Y. J. Shang, Q. L. Zeng, and L. H. Li, "Assessment of the degree of reinforcement demand (DRD) for rock slope projects-principles and a case example application," International Journal of Rock Mechanics and Mining Sciences, vol. 43, no. 4, pp. 531-542, 2006.

[21] Itasca Consulting Group Inc., Fast Lagrangian Analysis of Continua in 3-Dimensions (FLAC ${ }^{3 D}$ ) Version 5.0: User's Manual, Itasca Consulting Group Inc., Minneapolis, MN, USA, 2008.

[22] T. G. Sitharam, V. B. Maji, and A. K. Verma, "Practical equivalent continuum model for simulation of jointed rock mass using FLAC ${ }^{3 \mathrm{D}}$," International Journal of Geomechanics, vol. 7, no. 5, pp. 389-395, 2007.

[23] M. A. Llano-Serna, M. M. Farias, and D. M. Pedroso, "An assessment of the material point method for modelling large scale run-out processes in landslides," Landslides, vol. 13, no. 5, pp. 1057-1066, 2016.

[24] F. Zabala and E. E. Alonso, "Progressive failure of Aznalcóllar dam using the material point method," Géotechnique, vol. 61, no. 9, pp. 795-808, 2011.

[25] A. Yerro, E. E. Alonso, and N. M. Pinyol, "Run-out of landslides in brittle soils," Computers and Geotechnics, vol. 80, no. S1, pp. 427-439, 2016. 


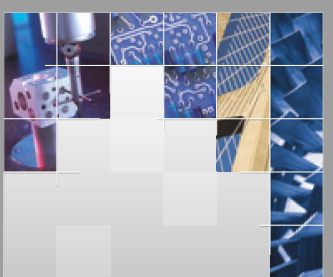

\section{Enfincering}
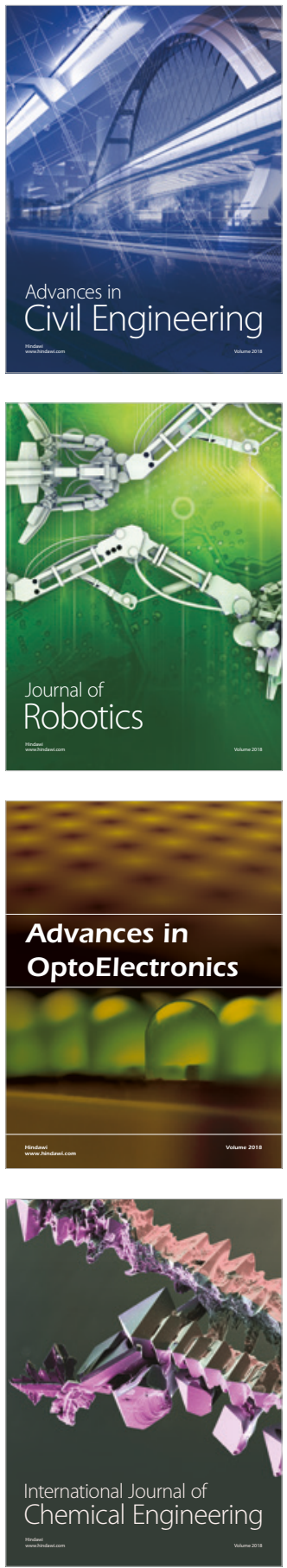

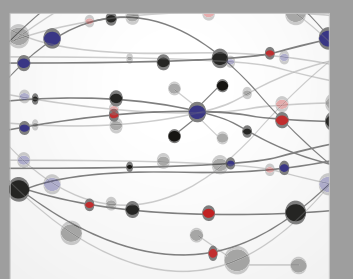

\section{Rotating \\ Machinery}

The Scientific World Journal

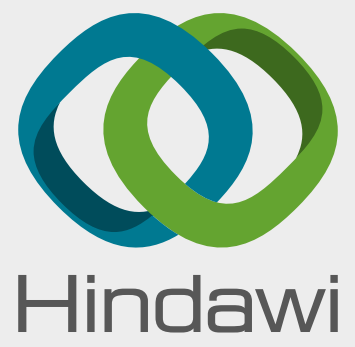

Submit your manuscripts at

www.hindawi.com
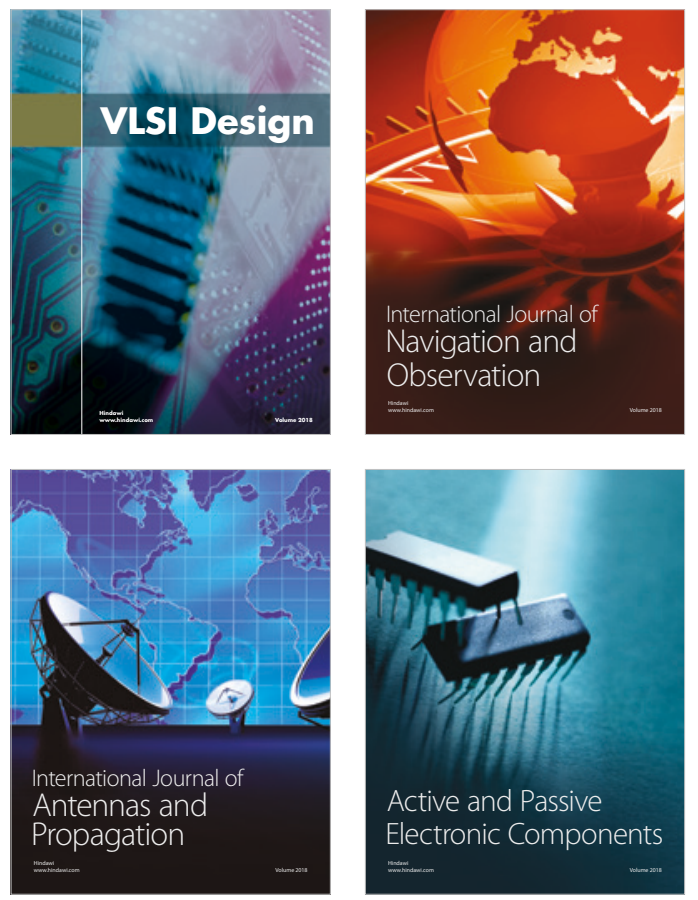
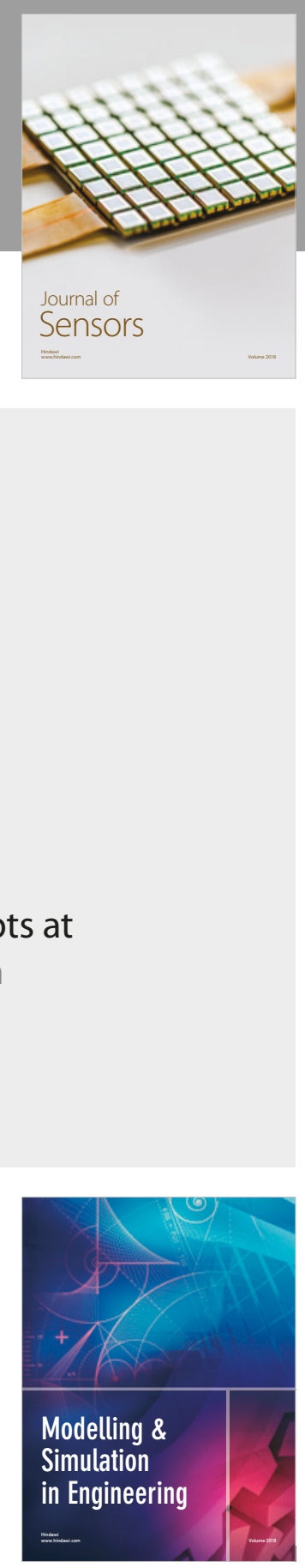

\section{Advances \\ Multimedia}
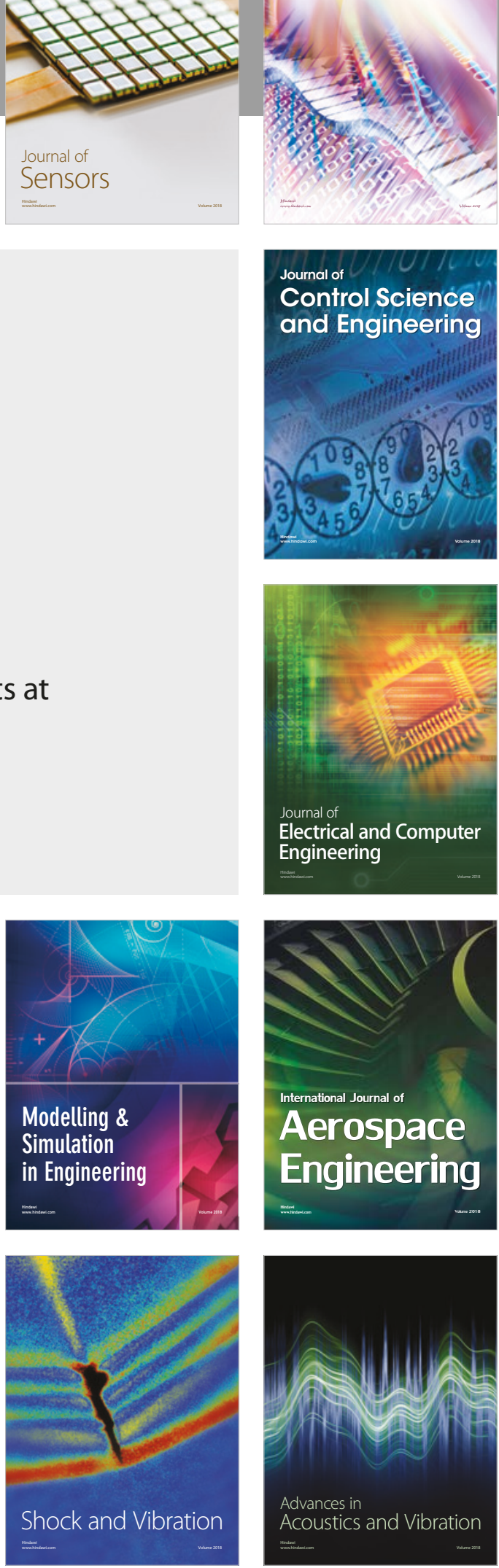